\title{
Generation of an engineered food-grade Lactococcus lactis strain for production of an antimicrobial peptide: in vitro and in silico evaluation
}

\author{
Abbas Tanhaeian ${ }^{1,2}$, Mehdi Mirzaii ${ }^{2}$, Zana Pirkhezranian ${ }^{3}$ and Mohammad Hadi Sekhavati ${ }^{3^{*}}$
}

\begin{abstract}
Background: Foodborne pathogens and their biofilms are considered as one of the most serious problems in human health and food industry. Moreover, safety of foods is a main global concern because of the increasing use of chemical food additives. Ensuring food safety enhances interest in discovery of new alternative compounds such as antimicrobial peptides (AMPs), which can be used as bio-preservatives in the food industry. In this study, the most important antimicrobial peptides of camel milk lactoferrin (lactoferrampin and lactoferricin) were recombinantly expressed in the form of chimeric peptide (CLFchimera) in a food-grade L. lactis strain. P170 expression system was used to express secreted CLFchimera using pAMJ1653 expression vector which harbors a safe (non-antibiotic) selectable marker.
\end{abstract}

Results: Peptide purification was carried out using Ni-NTA agarose column from culture medium with concentration of $0.13 \mathrm{mg} / \mathrm{mL}$. The results of disk diffusion test revealed that CLFchimera had considerable antimicrobial activity against a number of major foodborne bacteria. Furthermore, this chimeric peptide showed strong and weak inhibitory effect on biofilm formation against P. aeruginosa, S. aureus E. faecalis, and E. coli, respectively. Antioxidant activity and thermal stability of the chimeric peptide was determined. The results showed that CLFchimera had antioxidant activity $\left(\mathrm{IC}_{50}: 310 \mu / \mathrm{mL}\right)$ and its activity was not affected after $40 \mathrm{~min}$ of boiling. Finally, we evaluated the interaction of the peptide with LPS and DNA in bacteria using molecular dynamic simulation as two main intra and extra cellular targets for AMPs, respectively. Our in silico analysis showed that CLFchimera had strong affinity to both of these targets by positive charged residues after 50 ns molecular dynamic simulation.

Conclusions: Overall, the engineered food-grade L. lactis generated in the present study successfully expressed a secreted chimeric peptide with antimicrobial properties and could be considered as a promising bio-preservative in the food industry.

Keywords: Food-grade L. lactis, Antimicrobial peptide, Biofilm formation, Antioxidant activity, MD simulation

\footnotetext{
* Correspondence: Sekhavati@um.ac.ir

${ }^{3}$ Department of Animal Sciences, Faculty of Agriculture, Ferdowsi University of Mashhad, P.O. Box 91775-1163, Mashhad, Iran

Full list of author information is available at the end of the article
}

(c) The Author(s). 2020 Open Access This article is licensed under a Creative Commons Attribution 4.0 International License, which permits use, sharing, adaptation, distribution and reproduction in any medium or format, as long as you give appropriate credit to the original author(s) and the source, provide a link to the Creative Commons licence, and indicate if changes were made. The images or other third party material in this article are included in the article's Creative Commons licence, unless indicated otherwise in a credit line to the material. If material is not included in the article's Creative Commons licence and your intended use is not permitted by statutory regulation or exceeds the permitted use, you will need to obtain permission directly from the copyright holder. To view a copy of this licence, visit http://creativecommons.org/licenses/by/4.0/ The Creative Commons Public Domain Dedication waiver (http://creativecommons.org/publicdomain/zero/1.0/) applies to the data made available in this article, unless otherwise stated in a credit line to the data. 


\section{Background}

Foodborne pathogens and their biofilms are one of the serious problems of human health. Due to production of bacterial matrix during biofilm formation, bacteria are well protected against clinical antibiotics and thus it is difficult to eliminate them from food processing facilities [43], so introduction of effective methods is critical to prevent and remove biofilms to guarantee safe food production and preservation process $[24,44]$.

Today, shelf life and the safety of food products were enhanced by using natural or controlled microflora, mostly lactic acid bacteria [47] and natural components such as antimicrobial peptides (AMPs) [16].

As Lactococcus lactis are normally present in dairy products, replacement and establishment of these bacteria in the intestine can help human health by preventing invasion of pathogenic bacteria using reduction of intestine $\mathrm{pH}$ as well as production of natural antimicrobial compounds [7]. AMPs are a group of innate immune system molecules that contain 12-50 amino acids and exist in all organisms [38]. AMP has been known as a natural molecule with activity toward a broad spectrum of microorganisms including bacteria, fungi, and viruses [11]. Moreover, AMPs have been considered as a new generation of biologically active regulators that can prevent oxidation and microbial degradation in foods [35, 49].

In the present study, the recombinant expression of a chimeric form of peptide derived from camel milk lactoferrin (lactoferrampin + lactoferricin named cLFchimera) was achieved in a food-grade L. lactis strain. Lactoferrin has the ability to modulate the immune system as well as bacteriostatic activity $[41,53]$. Lactoferrampin and lactoferricin are two rich sources of hydrophobic and cationic antimicrobial peptides in N-terminus lactoferrin protein with activity toward a broad-spectrum of microorganisms including bacteria, fungi and viruses [8, 69]. Haney and co-workers [22] fused these two peptides and showed that the chimeric form has stronger antimicrobial activity compared to natural lactoferrin [22].

More recently, the recombinant form of cLFchimera has been cloned and expressed in E. coli [64] in our lab. The results of in vitro studies showed that this peptide has antibacterial [62, 64, 65], antiviral [61], and anticancer [63] properties. Furthermore, the results of an in vivo experiment showed that supplementing $E$. coli challenged broilers with cLFchimera improved villi morphology in the jejunum, restored microbial balance in the ileum, and improved gene expression of cytokines and tight junctions in the jejunum of challenged birds [14].

In this investigation, we generated an engineered food-grade $L$. lactis with the ability to secrete a chimeric peptide derived from camel lactoferrin into the culture medium. in vitro antibacterial, anti-biofilm and antioxidant activity of the recombinant chimeric peptide were determined on some food spoilage bacterial strains. Finally, using computational modeling approaches we try to predict peptide interaction to lipopolysaccharides (LPS) and DNA as two main targets in bacteria $[15,36,50,51]$.

\section{Methods}

Bacterial strains, vectors, growth conditions and other reagents

Lactococcus lactis AMJ1543 (Bioneer, Denmark) strain was used as the expression host. L. lactis strain AMJ1543 was grown at $30{ }^{\circ} \mathrm{C}$ in rich M17 medium supplemented with glucose and D-Alanine (2.25 mM, Sigma, USA). This strain is a D-Alanine auxotrophic strain and possesses a non-antibiotic-based alanine racemase selection system. The alr gene encodes alanine racemase protein which catalyzes the interconversion of L-Alanine to D-Alanine which is crucial for cell wall biosynthesis. D-Alanine is not a common ingredient in large-scale fermentation media, so the L. lactis strain AMJ1543 is not able to grow in the medium free of D-Alanine. Presence of pAMJ1653 expression vector which harbors alr encoding gene in L. lactis strain AMJ1543 can provide a condition in which LAlanine can be converted to D-Alanine by alanine racemase protein, so that it can be grown in M17 (Sigma, USA) medium without D-Alanine. The pAMJ1653 vector (Bioneer, Denmark, Fig. 1A) was used as an expression vector which contains specific L. lactis promoter and is up-regulated by low-pH [29]. Unless indicated otherwise, all chemicals, commercial kits and enzymes were obtained from Sigma Chemical (USA), Roche (Germany), New England Biolabs (England) and Thermo Fisher Scientific (USA) Companies, respectively.

\section{Gene synthesis and vector construction}

The chimeric lactoferricin and lactoferrampin consists of 36 amino acids and was generated through the fusion of two short regions of camel lactoferrin ${ }^{284}$ DLIWKLLVKAQEKFGRGKPS ${ }^{303}$ (ID: AHJ37525) and ${ }^{49}$ RVKKMRRQWQACKSS ${ }^{35}$ (ID:NP_001290496.1) linked by Lysine (GenBank accession number: MH327768). The chimeric peptide encoding sequence was codon optimized for the appropriate expression in L. lactis by Genscript ${ }^{\oplus}$ (USA). The restriction sites of SapI and SalI were added to the N and Cterminus of the chimera sequence for cloning in pAMJ1653 vector. The sequence was chemically synthesized by Generay Biotech (Shanghai, China). For vector construction, pAMJ1653 and pGH cloning vectors (a vector harboring synthetic gene) were sequentially digested by SapI (New England Biolabs, England) and SalI restriction enzymes (Thermo Fisher Scientific, USA). The digestion products were then 


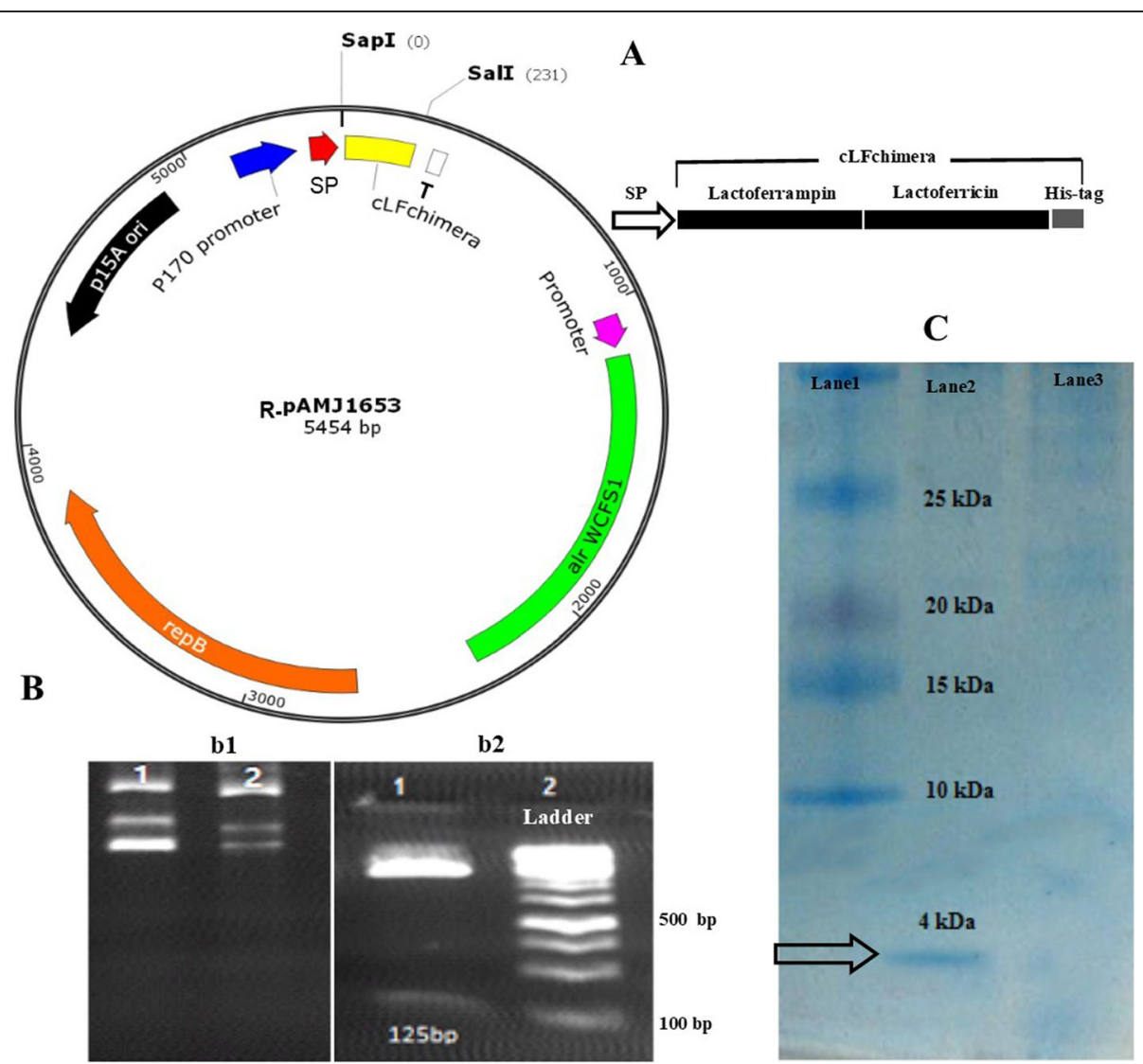

Fig. 1 A The schematic maps of recombinant PAMJ1653 vector (R-pAMJ1653) harboring CLFchimera and schematic representation of cLFchimera and its parts. P170 promoter, L. lactis promoter is up-regulated by low-pH; SP, signal sequence of SP310mut2; LFchimera, chimeric antimicrobial peptide, T, terminator; alr WCFS1, L. plantarum WCFS1 alr gene encoding alanine racemase; repB, a replicon from L. lactis for maintenance in L. lactis; p15A, a replicon from E. coli for maintenance in E. coli. B Restriction mapping analysis. b1) Undigested pAMJ1653 plasmid (Lane 1 and 2, refer to replicates); b2) Double digestion of recombinant pAMJ1653 vector by Sap/ and Sall. The size of the band of interest after double digestion is $125 \mathrm{bp}$. C SDS-PAGE analysis of the L. lactis culture supernatant. A protein band with the size of $4.2 \mathrm{kDa}$ (shown by arrow) represents the recombinant $C L F c h i m e r a$ peptide. From left to right: lane 1: size marker protein (ladder protein), lane 2: purified cLFchimera from culture supernatant of L. lactis harboring recombinant PAMJ1653 vector and lane 3: culture supernatant of L. lactis harboring self-ligated pAMJ1653 vector with no CLFchimera coding sequence was passed through Ni-NTA agarose column and was loaded on SDS-PAGE as negative control

purified and ligated by gel extraction and fast ligation kits (Thermo Fisher Scientific, USA), respectively.

\section{Peptide expression}

The competent cells of L. lactis strain AMJ1543 were initially prepared [27] and subsequently transformed by electroporation with an aliquot of the ligation reaction based on the protocol of electroporation for L. lactis strains [39]. The colonies harboring recombinant pAMJ1653 were first selected in growth medium free of D-alanine (M17 + glucose) at $30^{\circ} \mathrm{C}$ and then verified by colony polymerase chain reaction (PCR). The sequences of primers for recombinant constructs verification were PLF: 5'-CTGCCTCCTCTCCCTAGTGC-3' for the forward and PLR: 5'-CTAAGGATGATTTCTGGCAGGG3 ' for the reverse primer, respectively. PCR program was performed using the Personal Cycler $^{\text {rix }}$ thermo cycler (Biometra, Germany) with initial denaturation at $94{ }^{\circ} \mathrm{C}$ for $5 \mathrm{~min}$ followed by 35 cycles of denaturation, annealing and extension for $30 \mathrm{~s}$ at $94{ }^{\circ} \mathrm{C}, 30 \mathrm{~s}$ at $56^{\circ} \mathrm{C}$ and $30 \mathrm{~s}$ at $72{ }^{\circ} \mathrm{C}$, respectively. Finally, an additional cycle extension was carried out for $10 \mathrm{~min}$ at $72{ }^{\circ} \mathrm{C}$. The total volume of PCR reaction was $25 \mu \mathrm{L}$ with the reaction mixture containing $2.5 \mu \mathrm{L}$ of $10 \mathrm{X}$ PCR buffer, $2 \mu \mathrm{L}$ $\mathrm{MgCl}_{2}(50 \mathrm{mM}), 2 \mu \mathrm{L}$ dNTPs $(2.5 \mathrm{pmol} / \mu \mathrm{L}), 1.5 \mu \mathrm{L}$ of mix primer $(5 \mathrm{pmol} / \mu \mathrm{L}), 0.125 \mathrm{U} / \mu \mathrm{L}$ of EX Taq DNA polymerase (Takara, Japan) and deionized water up to $25 \mu \mathrm{L}$ reaction volume. The culture supernatant obtained from the transformant strain of $L$. lactis was first evaluated for the production and accumulation of the heterologous peptide using the disk diffusion test, and subsequently analyzed by SDS polyacrylamide gel electrophoresis (SDS-PAGE). The recombinant L. Lactis was grown in M17 medium at $30^{\circ} \mathrm{C}$ for $16 \mathrm{~h}$ and then $15 \mu \mathrm{L}$ of culture supernatant was electrophoresed on SDSPAGE in Tris/glycine/SDS buffer using 17.5\% acrylamide 
gels and visualized using Coomassie Brilliant Blue staining protocol. The expressed peptide was purified using Ni-NTA agarose column (Thermo, USA) according to the manufacturer's instructions. The quality and quantity of purified recombinant cLFchimera was analyzed on a $17.5 \%$ SDS-PAGE gel electrophoresis and Bradford method [9], respectively.

\section{Antibacterial activity tests}

The foodborne bacterial strains: Escherichia coli (ATCC 25404), Staphylococcus aureus (ATCC 15981), Salmonella typhimurium (ATCC 14028), Enterococcus faecalis (ATCC 47077), Listeria monocytogenes (ATCC 19111) and Pseudomonas aeroginosa PAO1 were kindly provided from the bacterial collection in the Department of Food Science and Technology, Ferdowsi University of Mashhad, Iran. The disc diffusion method was performed to determine the rate of bacterial inhibition by culture supernatant. Various volumes of culture supernatant of transformed cells $(10,20$ and $40 \mu \mathrm{L})$ were loaded as peptide solution on $6 \mathrm{~mm}$ sterile paper discs. Each loaded disc was placed on the surface of a Muller Hinton Agar petri dish and incubated at $37^{\circ} \mathrm{C}$ for $16 \mathrm{~h}$. The discs loaded by standard antibiotic Penicillin (10 $\mathrm{mg} / \mathrm{disc})$ and Gentamicin (10 mg/disc) as well as $40 \mu \mathrm{L}$ of culture supernatant obtained from transformed L. lactis by vector with no cLFchimera coding sequence were used as positive and negative control respectively. Antimicrobial activity was evaluated by measuring the diameter of the inhibition zone around the discs $(\mathrm{mm})$. As maintained by the Clinical and Laboratory Standards Institute (CLSI) the minimum inhibitory concentrations (MICs) of the cLFchimera were measured in Broth microdilution [17, 28]. In summary, Mueller Hinton Broth (Cation-adjusted) that contains increasing concentrations of cLFchimera is inoculated with specific number of cells (approx. $5 \times 10^{5} \mathrm{CFUs} / \mathrm{mL}$ ) in micro-titer plates (polypropylene), while each plate includes a positive and negative control. After incubation, the MIC concentration of AMPs is defined as the lowest concentration inhibiting visible growth of bacteria after overnight incubation. All plates were incubated for $18-20 \mathrm{~h}$. The MIC measurements were carried out in triplicate.

\section{Phenotypic biofilm assay}

Semi-quantitative determination of biofilm formation was performed in triplicate by colorimetric microtiter plate as previously described [30]. Pure cultures of $S$. aureus ATCC 15981, E. coli ATCC 25404, P. aeroginosa PAO1 and E. faecalis ATCC 47077 were used. Briefly, the strains were cultured in $5 \mathrm{~mL}$ tryptic soy broth (TSB; DIFCO, Becton Dickinson, Franklin Lakes, NJ, USA) with $1 \%$ glucose (Glc) for $18 \mathrm{~h}$ at $37^{\circ} \mathrm{C}$ and treated with cLFchimera (50\% of the MIC) or control medium. The cultures were diluted (1:100) in the same medium, $200 \mu \mathrm{L}$ was inoculated in a 96-well plate, and plates were incubated at $37^{\circ} \mathrm{C}$ for $24 \mathrm{~h}$. The plates were washed twice with phosphatebuffered saline (PBS), dried for $1 \mathrm{~h}$ at $65^{\circ} \mathrm{C}, 1 \%$ crystal violet was added, and the plates were incubated for a further $30 \mathrm{~min}$ at $25^{\circ} \mathrm{C}$. Each well was washed twice with PBS and $200 \mu \mathrm{L}$ PBS was added prior to measuring absorbance at $590 \mathrm{~nm}$ using a microplate reader (state fax3100, USA). All strains were tested in quadruplicate in two independent experiments. The cut-offs proposed by Stepanović et al. [60] were used to classify the level of biofilm production. The uninoculated medium was used, as control, to determine the background OD. The cut-off OD (ODc) was defined as three standard deviations above the mean OD of the negative control and the final OD value, of a tested strain, was defined as the average OD of the strain reduced by the ODc value. The adherence ability of the tested strain was classified into four categories based on the OD: non-adherent $(\mathrm{OD}<\mathrm{ODc})$, weakly adherent (ODc $<$ OD $<2$ XODc), moderately adherent (2XODc $<$ $\mathrm{OD}<4 \mathrm{XODc})$, and strongly adherent $(4 \mathrm{XODc}<\mathrm{OD})$.

\section{Antioxidant activity of cLFchimera}

The antioxidant activity was determined using 2, 2Diphenyl-l-picrylhydrazyl (DPPH) as a free radical as previously described [10]. Briefly, peptide solution in methanol $(0.1 \mathrm{~mL})$ was added to $3.9 \mathrm{~mL}$ of a $6 \times 10^{-5} \mathrm{~mol} / \mathrm{L}$ methanol DPPH solution. The decrease in absorbance was determined at $515 \mathrm{~nm}$ at $0 \mathrm{~min}, 1 \mathrm{~min}$ and every $15 \mathrm{~min}$ until the reaction reached a plateau. Inhibitory effect of cLFchimera was determined as follows: [OD DPPH solution (control) - OD treatment (cLFchimera)/DPPH solution] $100 \%$. Antiradical activity was defined as the amount of antioxidant necessary to decrease the initial DPPH concentration by $50 \%$ (Efficient Concentration $=\mathrm{EC}_{50}$ ).

\section{Thermal stability of recombinant peptide}

Forty microliter volumes of the culture supernatant were boiled at $100^{\circ} \mathrm{C}$ at different times including $0,10,20$, and $40 \mathrm{~min}$. The antibacterial activity was determined against S. aureus ATCC 25923 using disc diffusion method according to the method described above.

\section{In silico analysis}

BDNA structure was obtained from the Protein Data Bank (1BNA). The cLFchimera were modeled using Modeller 9.2 [19]. LPS structure was derived from Gram-negative bacteria membrane which was obtained from Prof, Xalid Syma [33]. The accuracy of the predicted models was examined using Ramachandran plot analysis in PROCHECK http://servicesn.mbi.ucla.edu/PROCHECK/ [34]. The complex of BDNA-cLFchimera and LPS-CLFchimera was studied by molecular dynamics simulation (MD) with GROMACS 2016.1 package with periodic boundary 
conditions in all directions $[1,5,70]$. AMBER94 force field [21] for DNA*peptide and the GROMOS 53A6 force field [45] for LPS*peptide interactions were used. The longrange electrostatic interactions were calculated using particle-mesh Ewald (PMD) method, whereas the van der Waal interactions were treated with smooth cutoff at a distance of $12 \mathrm{~A}^{\circ}$ [31]. All the systems were solvated in cubic water box with Simple Point Charge (SPC) water model [4]. To neutralize the entire system $\mathrm{Na}^{+}$and $\mathrm{Cl}^{-}$ ions were added by substituting the water molecules. Energy minimization was performed using steepest descent algorithm for 50,000 cycles. Further, minimized system was equilibrated into the isothermal-isobaric (NPT) phases for 1000 ps at a constant pressure of 1 bar with Parrinello-Rahman pressure coupling method [42] and a temperature of $300 \mathrm{~K}$ with Nosé-Hoover temperature coupling method [20]. The equilibrated systems were used for a production run at $300 \mathrm{~K}$ and 1 bar pressure for 50 , 000 ps. To increase the accuracy every system was simulated in three replicates. Dynamic behavior and stability of each system were analyzed including root mean square deviation (RMSD), center of mass distances (COM) and hydrogen bond using Gromacs in-built tools. Binding free energy was calculated using molecular mechanics/Poisson Boltzmann surface area (MM/PBSA) estimation. The $\mathrm{MmPbSaDecomp}$.py python script was used to estimate the contribution of each residue to the total binding free energy $[31,33]$.

\section{Statistical analysis}

All assays were performed with three biological replications and the calculations were made to determine the average of diameters for inhibition zones. Data sets were subjected to analysis of variance (ANOVA) and Duncan's multiple range test using SAS software (SAS 9.1).

\section{Results \\ Design and vector construction}

The results of restriction digestion (Fig. 1b2) and sequencing showed that cLFchimera coding sequence was successfully cloned into pAMJ1653 vector in the correct frame (Fig. 1A) without any mutation. The colonies transformed by pAMJ1653 vector were analyzed by colony PCR using P170 specific primers which amplified $125 \mathrm{bp}$ fragment in culture medium without alanine.

\section{Transformation of $L$. lactis and peptide expression}

L. lactis harboring recombinant pAMJ1653 vector was selected through colony PCR by specific primers on a single colony. The expression of the chimeric peptide in harvested supernatant was evaluated by SDS-PAGE analysis. As expected, a $4.2 \mathrm{kD}$ protein band corresponding to the size of cLFchimera was observed in the gel; suggesting that the peptide was properly expressed in AMJ1543 strain and secreted into medium culture (Fig. 1C). The His-tag purified peptide concentration was $0.13 \mathrm{mg} / \mathrm{mL}$.
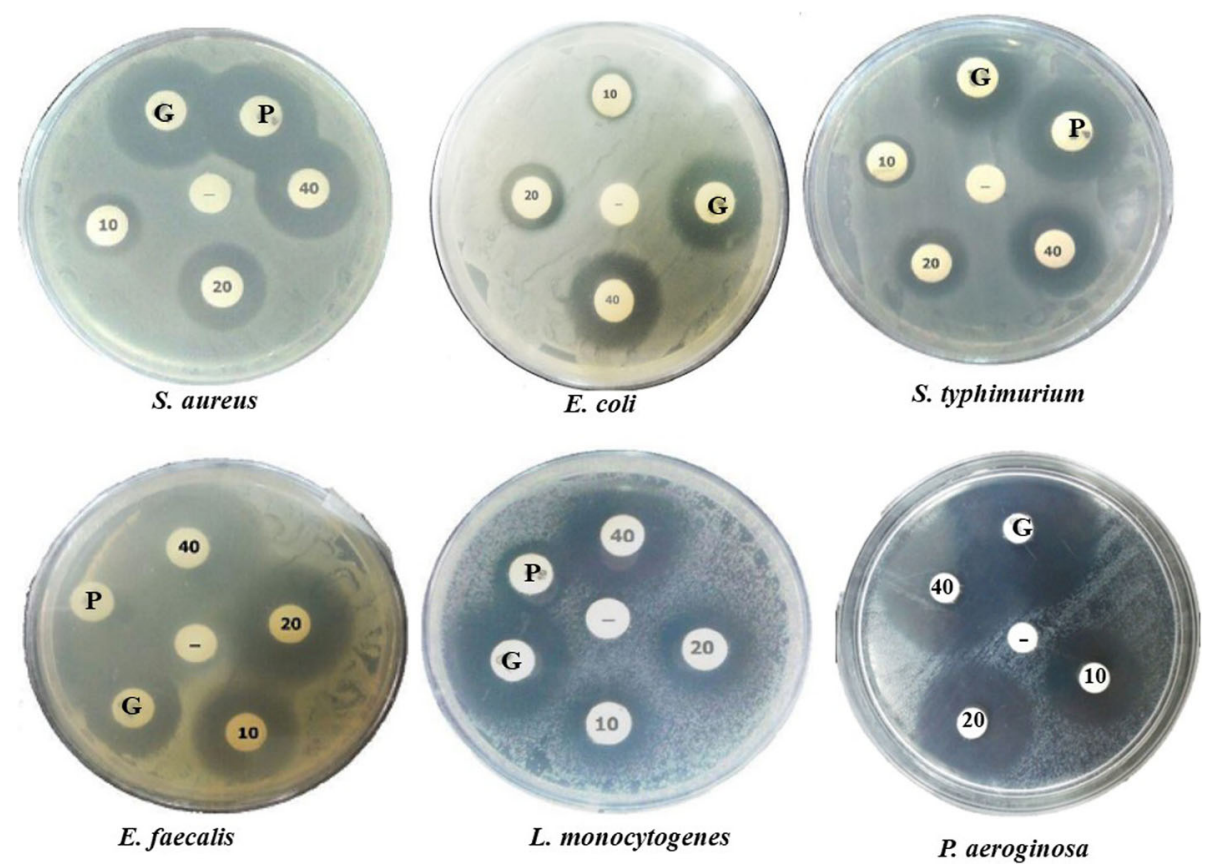

Fig. 2 The result of disc diffusion assay for the candidate pathogens in this study. Three different volumes of culture supernatant containing the chimeric peptide (10, 20 and $40 \mu \mathrm{L})$ were considered as treatments. $+\mathrm{C}$ : Penicillin $(\mathrm{P}, 10 \mathrm{mg} / \mathrm{disc})$ and Gentamicin $(\mathrm{G}, 10 \mathrm{mg} / \mathrm{disc}),-\mathrm{C}: \mathrm{culture}$ supernatant of L. lactis harboring self-ligated pAMJ1653 vector 
Table 1 Antimicrobial activity of the chimeric peptide evaluated by disc diffusion method

\begin{tabular}{|c|c|c|c|c|c|}
\hline \multirow[t]{2}{*}{ Bacterial species } & \multicolumn{3}{|c|}{ Volume of supernatant $(\mu \mathrm{L})$} & \multirow{2}{*}{$\begin{array}{l}\text { Positive control } \\
\text { Gentamicin }\end{array}$} & \multirow{2}{*}{$\begin{array}{l}\text { Negative } \\
\text { control }\end{array}$} \\
\hline & 10 & 20 & 40 & & \\
\hline S. aureus & $11.1 \pm 0.14^{c}$ & $15.8 \pm 0.14^{b}$ & $21.1 \pm 0.14^{\mathrm{a}}$ & $20.1 \pm 0.14^{a}$ & - \\
\hline E. coli & $9.1 \pm 0.17^{c}$ & $13.8 \pm 0.17^{b}$ & $16.2 \pm 0.17^{\mathrm{a}}$ & $15.8 \pm 0.17^{\mathrm{a}}$ & - \\
\hline S. typhimurium & $11.2 \pm 0.33^{c}$ & $13.9 \pm 0.33^{b}$ & $18.4 \pm 0.33^{\mathrm{a}}$ & $19.0 \pm 0.33^{\mathrm{a}}$ & - \\
\hline L. monocytogenes & $11.1 \pm 0.50^{c}$ & $16.6 \pm 0.5^{b}$ & $21.3 \pm 0.5^{a}$ & $21.3 \pm 0.5^{a}$ & - \\
\hline E. faecalis & $20.8 \pm 0.32^{d}$ & $24.5 \pm 0.32^{c}$ & $28.6 \pm 0.32^{b}$ & $30.1 \pm 0.32^{a}$ & - \\
\hline P. aeroginosa & $21.0 \pm 0.22^{d}$ & $24.2 \pm 0.22^{c}$ & $27.6 \pm 0.22^{b}$ & $31.1 \pm 0.22^{\mathrm{a}}$ & - \\
\hline
\end{tabular}

The data are the inhibition zone around the discs $(\mathrm{mm})$ loaded by different volume of supernatants containing recombinant peptide and antibiotic. The data are presented as average values of three replicates with their standard error. Negative control: M17 cultured with non-recombinant $L$. lactis. Means with different letter(s) are significantly different based on DUNCAN multiple test $(a=0.05)$. - representing no growth inhibition

\section{Evaluation of antibacterial activity}

For evaluation of peptide functionality, the medium containing cLFchimera was examined for antibacterial activity using disc diffusion assay. The results indicated that the medium containing the chimeric peptide had antibacterial effect against $E$. coli (ATCC 25404), S. aureus (ATCC 15981), S. typhimurium (ATCC 14028), E. faecalis (ATCC 47077), L. monocytogenes (ATCC 19111) and P. aeroginosa PAO1 (Fig. 2).

Moreover, the statistical analysis of inhibition zone diameters showed a significant difference between diverse amounts of cultural medium containing recombinant peptide against all foodborne bacteria $(p>0.0001)$. The results are presented in the Table 1.

\section{Phenotypic biofilm assay}

The effect of cLFchimera on biofilm formation was evaluated against $P$. aeruginosa, $S$. aureus, $E$. faecalis and $E$. coli bacteria. To this end, MIC for cLFchimera was determined by purified cLFchimera (Table 2) and then the inhibitory effect of this peptide was examined on biofilm formation by phenotypic biofilm assay. Based on the phenotypic biofilm results, the highest and the lowest inhibitory effect of cLFchimera was observed on S. aureus, $P$. aeruginosa E. coli, and E. faecalis, respectively (Fig. 3A).

\section{Antioxidant activity and thermal stability of recombinant peptide}

$\mathrm{DPPH}$ as a free radical was used for determining the antioxidant activity of cLFchimera. Our results showed that cLFchimera reacted rapidly with the DPPH.

Table 2 Minimum inhibitory concentration (MIC) of the CLFchimera against some foodborne pathogens

\begin{tabular}{lll}
\hline Bacteria & Source & MIC $(\mu \mathrm{g} / \mathrm{mL})$ \\
\hline P. aeroginosa & PAO1 & 28.6 \\
S. aureus & ATCC 15981 & 93.11 \\
E. faecalis & ATCC 47077 & 3.12 \\
E. coli & ATCC 25404 & 44.33 \\
\hline
\end{tabular}

Absorbance at $517 \mathrm{~nm}$ was dramatically decreased with increasing the amount of chimeric peptide and reached the minimum at $300 \mu \mathrm{g} / \mathrm{mL}$. At this peptide concentration (IC50: $300 \mu \mathrm{g} / \mathrm{mL}$ ) approximately $50 \%$ of DPPH was inactivated by chimeric peptide. Interestingly, by increasing the peptide concentration the antioxidant activity decreased (Fig. 3B). Finally, thermal stability analysis of the chimeric peptide showed that the temperature corresponding to $100{ }^{\circ} \mathrm{C}$ for $40 \mathrm{~min}$ had no significant effect on its antibacterial activity against $S$. aureus as a Grampositive bacterial model as shown in Fig. 3C.

\section{Validation of 3D cLFchimera structure}

The generated model for the cLFchimera was examined for overall model quality prior to simulation. The Ramachandran plot obtained for the cLFchimera revealed that $92.3 \%$ of the residues were situated within the most favored region, while $7.7 \%$ residues of CLFchimera were found within the additional allowed region. This result shows the obtained model was consistent and could be used in molecular dynamics analyses.

\section{Molecular dynamic analysis}

To better understand the possible mode of action for cLFchimera, DNA and LPS were candidates as extra and intra-cellular targets in MD analysis, respectively. RMSD was calculated as one of the most common measures of structural fluctuations during simulation. The results show that interaction of the chimeric peptide to both of the targets increased the RMSD value which indicated the change of peptide structure through binding to these two targets. Change in peptide structure when it interacts with LPS was significantly higher than DNA peptide interaction (Fig. 4).

To monitor the distance between peptide and targets during MD simulation the center of mass distance analysis was performed. Side view of snapshots at first and last ns are shown in Fig. 5b and c. COM distances were initially set as approximately 3.5 and $3 \mathrm{~nm}$ for cLFchimera*DNA and cLFcimera*LPS, respectively (Fig. 5a and 
$\mathbf{A}$

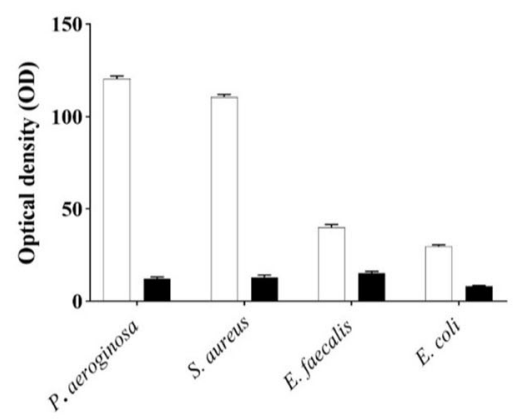

- cLFchimera

+ cLFchimera

B

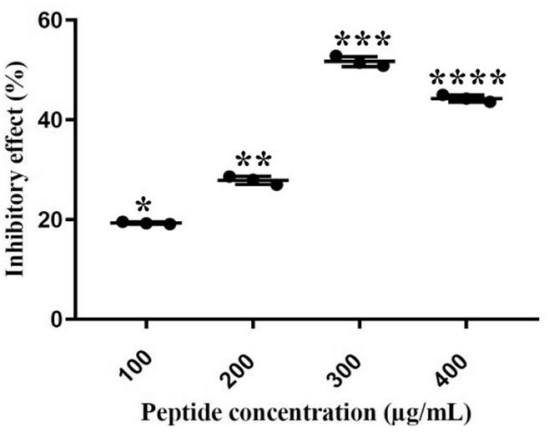

C

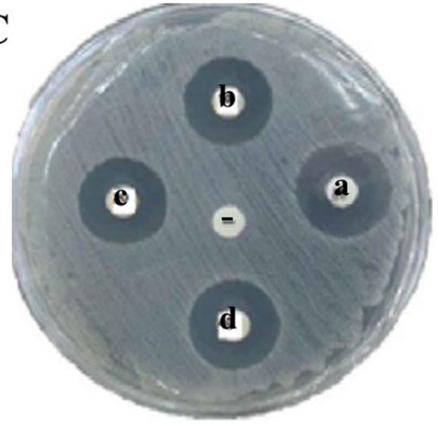

Fig. 3 A Inhibitory effect of CLFchimera on biofilm formation which was determined by phenotypic biofilm assay. The absorbance was measured at $590 \mathrm{~nm}$. +CLFchimera: treated with peptide; -CLFchimera: un-treated with peptide. B Inhibitory effect of CLFchimera on DPPH as a free radical. C The results of thermal stability of recombinant chimeric peptide against $S$. aureus for three different periods of boiling $(a, b$ and $c$ referred to 10 , 20 and 40 min, respectively). d: Penicillin (10 mg/disc), -: culture supernatant of L. lactis harboring self-ligated pAMJ1653 vector. * It referred significantly to different levels of peptide concentration. The average percentage of inhibitory effect with different number of asterisk (s) is significantly different based on DUNCAN multiple test $(a=0.05)$

cyan snapshots in Fig. $5 \mathrm{~b}$ and c). The peptide instantly moved toward the DNA grooves and LPS (Lipid A) and COM distances decreased rapidly compared to their initial state as illustrated in Fig. 5a. and the green snapshots in Fig. 5c. Based on our results the peptide showed high affinity to lipid A as a main target for AMPs in Gramnegative bacteria.

For having a deeper view in peptide*LPS and peptide"DNA complexes, the number of hydrogen bonds formed between peptides and targets was calculated (Fig. 6a and b). On average, there were about 5 and 4 hydrogen bonds between the peptide and LPS and DNA, respectively. For example, there were 5 hydrogen bonds in Fig. 6c, between ARG22, GLN29, ARG16, LYS9 and LYS5 and DNA and also 5 hydrogen bonds in Fig. 6d between SER20, LYS24, LYS34, LYS21, and GLN31 and LPS. Considering that hydrogen-bond forming has a main role in stabilizing protein"DNA and protein"LPS complexes, cLFchimera would

RMSD

r_44-85 after 1sq fit to $\mathbf{r} \_44-85$

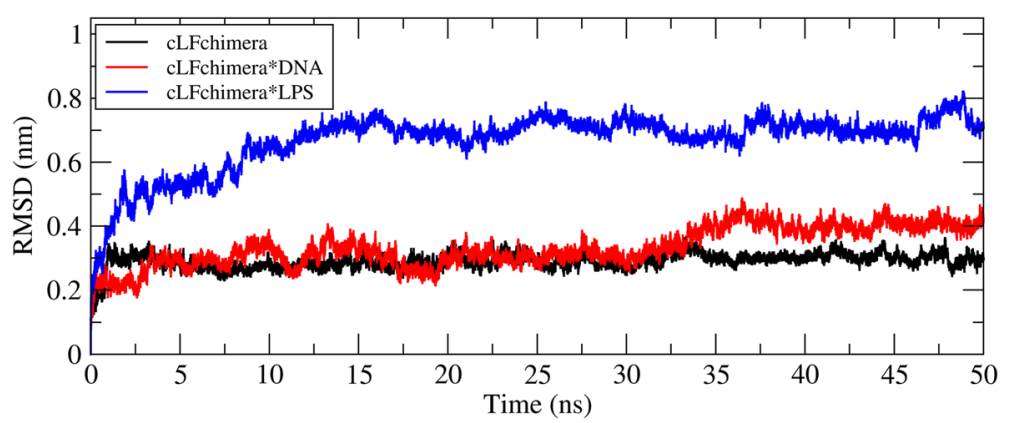

Fig. 4 Time evolution of the RMSD, computed through least square fitting of backbone atom 


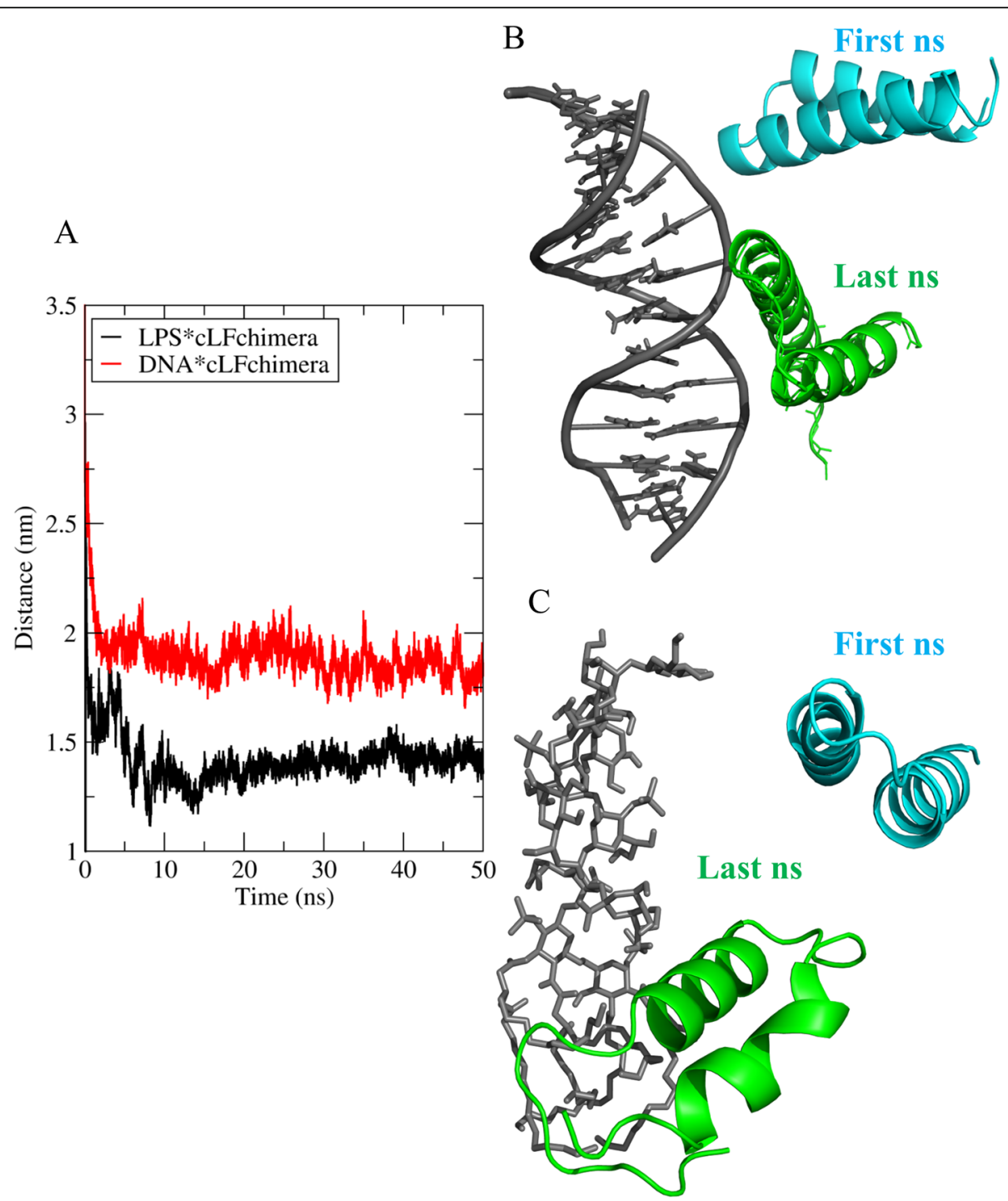

Fig. 5 A representative trajectory of the distance decrease during simulation. a Center of mass distances for LPS*CLFchimera (red) and

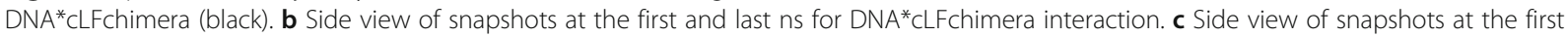
and last ns for LPS*CLFchimera interaction

have a proper stable interaction with these targets. Hydrogen bonding values shown behaved similarly in all replicates.

The binding free energy analysis was calculated using the MM/PBSA method. The results showed that cLFchimera"DNA and cLFchimera"LPS had a strong binding energy $720 \mathrm{~kJ} / \mathrm{mol}$ and $514 \mathrm{~kJ} / \mathrm{mol}$, respectively. The contribution of residues in cLFchimera*DNA and cLFchimera*LPS complexes were screened and the corresponding binding energy was calculated with the MmPbSaDecomp.py python script. The result demonstrated that residues LYS5, LYS9, LYS13, ARG16, LYS18, LYS21, ARG22, LYS24, LYS25, ARG27, ARG28, LYS34 and LYS35 are the key residues for compounds binding in the CLFchimera*DNA and cLFchimera"LPS interactions. However, both GLU12 and SER36 have a negative effect on total binding energy due to their negative charges (Fig. 7).

\section{Discussion}

Generation of engineered food-grade bacteria to produce and deliver therapeutic agents is a hopeful approach for the development of new therapies for gastrointestinal tract disorders $[58,68]$. One such bacterium, L. lactis, is routinely used for heterologous protein expression in therapeutic and industrial applications [40, 59]. Moreover, $L$. lactis is classified 'generally recognized as safe' (GRAS) by the Food and Drug Administration (FDA) [6]. Therefore, this system could be an interesting expression platform in food industry area. As was mentioned above, the main aim of this study was to express an 

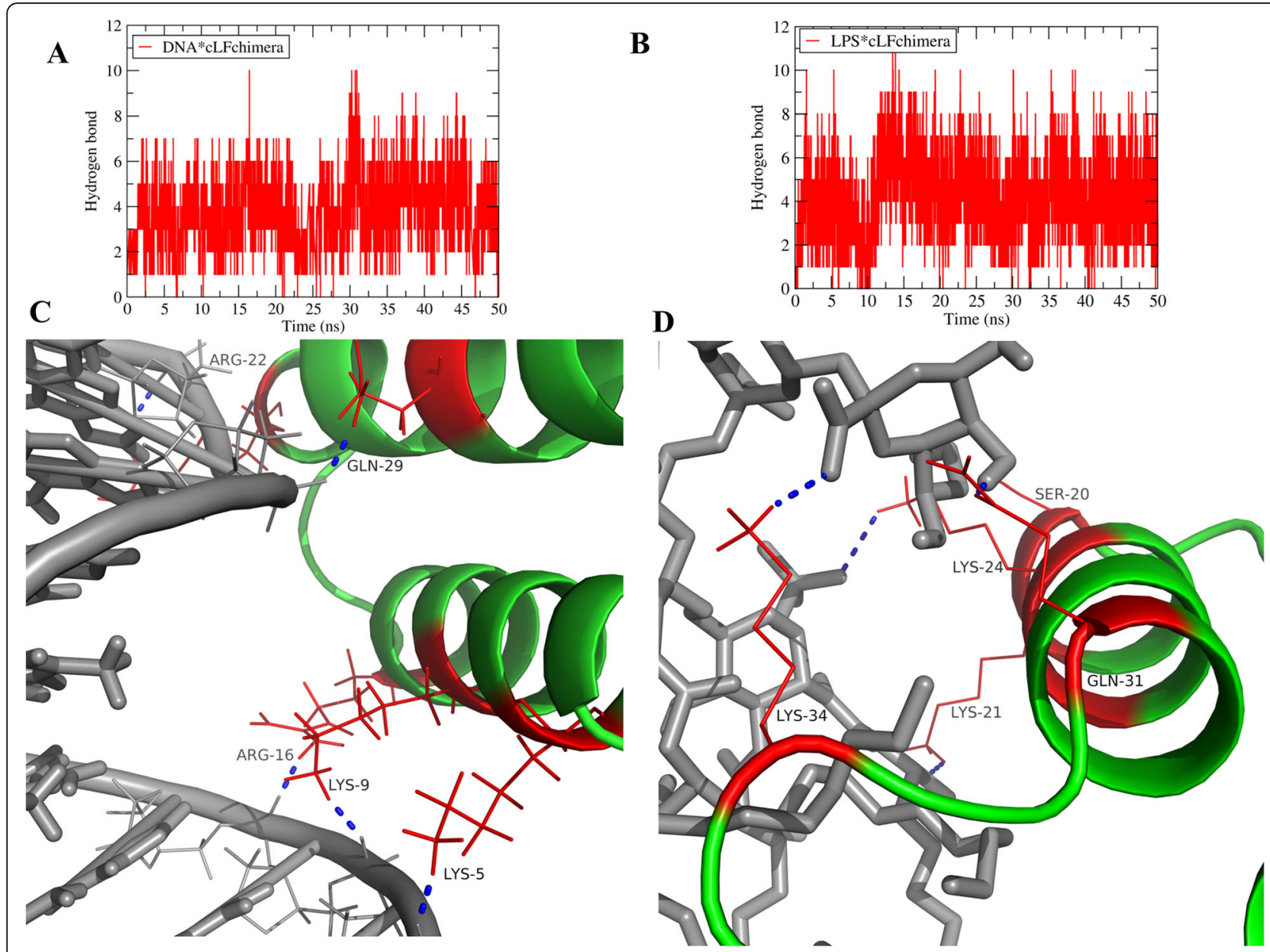

D

Fig. 6 The number of hydrogen bonds between a DNA and CLFchimera, $\mathbf{b} L P S$ and CLFchimera. Snapshot at the $t=50 \mathrm{~ns}$ for DNA and CLFchimera (c) and LPS and CLFchimera (d), the blue dash lines represent the hydrogen bond

antimicrobial peptide in $L$. lactis. Our results showed that the recombinant camel chimeric lactoferricin and lactoferrampin (cLFchimera) was successfully expressed in L. lactis and showed antimicrobial activity against different foodborne pathogens. Our results were well in accordance with other studies which showed antibacterial activity of bovine chimeric lactoferricin and lactoferrampin $[8,69]$. (The P170 expression system offers a series of vectors designed for protein secretion by means of SP310mut2, an optimized version of a SP from a native lactococcal protein with the ability to promote efficient protein secretion [29]. The presence of secretion signal peptide SP310mut2 in this expression system allows secretion of recombinant peptide in the medium immediately after synthesis, providing the possibility to use this peptide without any extra process. The efficacy of the P170 expression system for secretion has recently been proven [29] and reconfirmed in our study. The recombinant chimeric peptide was successfully expressed in L. lactis strain AMJ1543, a mutant strain which does not have the ability to synthetize Alanine racemase and was previously selected in an alanine-free medium. Due to the lack of antibiotics as a selectable marker, it will be quite safe to use this platform for oral consumption in the future.

The chimeric synthesized recombinant peptide is one of the most hydrophobic peptides. It has been shown that the hydrophobic antimicrobial peptide can recognize the anionic lipids situated in the external surface of bacterial membrane. Attachment of this antimicrobial peptide to the bacterial membrane and subsequently their accumulation inside the membrane causes pores formation and bacterial death [32, 74]. This could be the possible mechanism of antimicrobial activity of the recombinant peptide used in this study.

In the present study we used some foodborne pathogens in the food industry to test the antimicrobial activity of the synthesized recombinant peptide. The desired inhibition was observed against all bacteria treated with the recombinant peptide. Stronger antimicrobial activity was observed in higher peptide concentration. The antibacterial activity of 

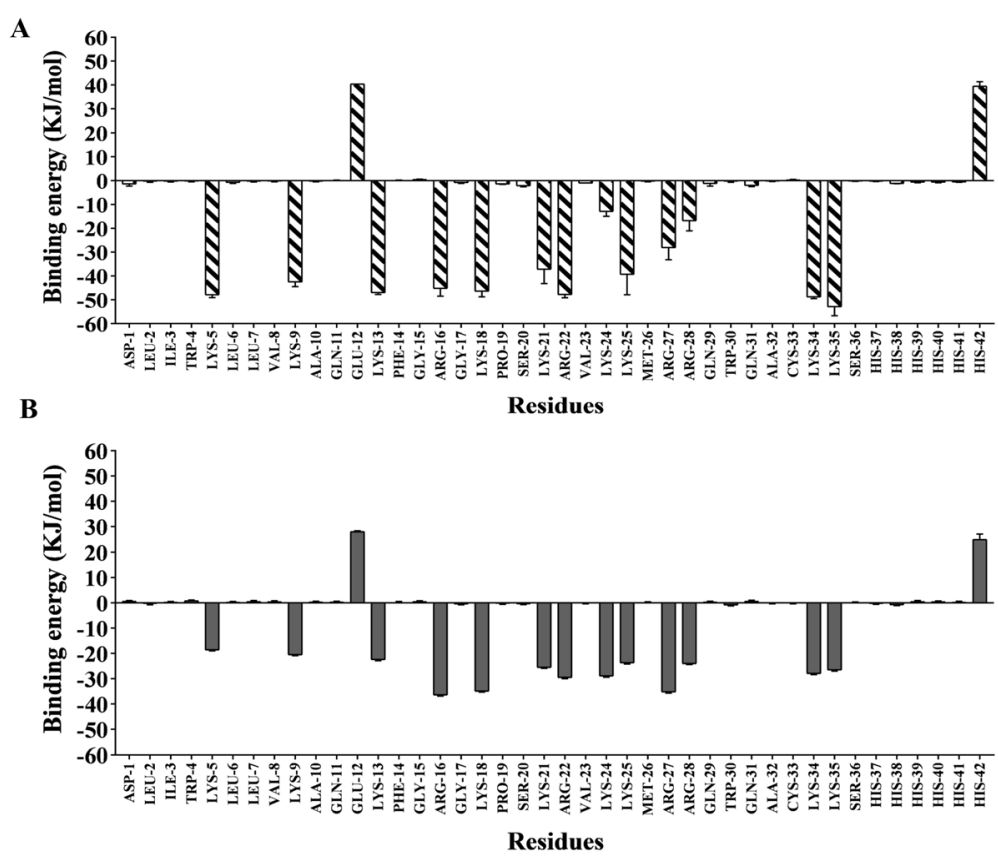

Fig. 7 The contribution of residues to the binding energy for active compounds

bovine chimeric lactoferricin and lactoferrampin against Salmonella typhimurium as a negative and Staphylococcus aureus as a Gram-positive bacterium has been proven by other researches and results showed that this recombinant peptide has antibacterial activity against both types of Gram-positive and Gram-negative bacteria [57, 66]. The camel recombinant peptide used in this study also showed an effective antibacterial activity against Gram-positive $S$. aureus, E. faecalis and L. monocytogenes, as well as Gramnegative P. aeruginosa, E. coli and S. typhimurium. Several studies showed that L. Lactis has antimicrobial activity against some pathogenic bacteria [3]. Nisin and secreted lactic acid $(\mathrm{pH})$ are two well-characterized antibacterial agents of L. lactis. However, in our results we did not observe any inhibitory zone in the disc diffusion assay for culture supernatant of $L$. lactis harboring self-ligated pAMJ1653 vector as negative control after $24 \mathrm{~h}$ of incubation even in $40 \mu \mathrm{L}$. These observations were likely due to the low concentration of these antibacterial agents in that volume of culture supernatant or short time of incubation.

After purifying the chimeric peptide from culture supernatant, anti-biofilm formation and antioxidant activities were examined. cLFchimera showed strong antibiofilm formation against $S$. aureus and $P$. aeruginosa and moderate effect on E. coli and E. faecalis. Wakabayashi et al. [71] showed that both human and bovine lactoferrin had inhibitory effect on biofilm formation against $P$. gingivalis and $P$. intermedia [71]. While antibiofilm effect of lactoferrin and its derivatives has been demonstrated, the mode of action remains an area of active research $[2,56]$. The most obvious mechanism of lactoferrin action is removal of iron in the environment, thus limiting the capacity of the biofilm to survive. However, some evidence suggests that lactoferrin interaction with the biofilm may be more complex [72].

Safaeian and Zabolian [54] reported that oral administration of bovine lactoferrin strongly reduced the production of reactive oxygen species (ROS) by inhibition of oxidative stress [54]. In another study, in vitro antioxidant activity of lactoferrin was evaluated by scavenging capacities against DPPH free radicals and the results showed that lactoferrin had obvious lipid peroxidation inhibitory activity [37]. In parallel with these findings, cLFchimera showed antioxidant activity and reacted rapidly with the DPPH. Interestingly, with increasing the peptide concentration the antioxidant activity decreased which may indicate the peptide interacts with other peptides in high concentration and therefore, loses the opportunity to interact with DPPT as free radical.

The thermal processing method is usually used for different stages of the food industry. For example, it can be important in sterilizing high resistance proteins such as lactoferrin [18]. The thermal stability of lactoferrin has already been reported [13]. The chimeric peptide derived from camel lactoferrin also showed reasonable thermal stability which could be considered in industrial processes.

AMPs usually mediate their antibacterial activity using two well-known mechanisms including extra and intracellular actions. LPS [36] and DNA [15] are two 
candidates considered as the targets of AMPs. Several studies indicated that AMPs initially interact with LPS as the main extra-cellular targets and then mediate their action by cell membrane disruption. The most important parts of LPS for AMPs binding are known as Lipid A [52]. Our in silico analysis showed that cLFchimera had strong affinity to Lipid A which is in accordance with the findings of Rossi et al. [52]. Numerous studies revealed nucleic acids have been proven as intracellular targets for some antimicrobial peptides such as MDpep9 [67], Buforin I [48], Indolicidin [23], Cecropin PR39 [26], and NK18 [73]. Binding of AMPs to major groove of DNA is likely due to positive charge of these peptides which interacts with negative DNA charge [55]. In parallel to this finding, the amount of electrostatic energy binding obtained in our results was the main considerable part of total free energy binding which confirmed the previous results [46]. In both cLFchimera*LPS and cLFchimera"DNA interactions the same residues of peptide acted as active compounds. Based on our contribution analysis, LYS 5, 9, 13, 18, 21, 24, 25, 34, 35 and ARG16, 22, 27 have the negative binding energy, therefore, they are the key residues for these complex formations. According to different charge between peptide and targets these results are rational. However, our results indicate that GLU 12 and HIS 42 were an inhibitor for these interactions. Considering the negative charge of GLU 12 this result was predictable. HIS 42 sometimes has positive charge in physiological pH. So, the presence of this AA as an inhibitor residue in this interaction was a surprising result.

Regarding the possibility of using $L$. lactis expression system in dairy products [25], it seems that our developed expression system in the present study could be used as a food preservative in dairy products. Moreover, the growth ability of L. lactis in acidic $\mathrm{pH}$ and the optimal stability of this bacterium in the gastrointestinal tract, along with its ability to inhibit pathogenic bacteria in intestine [12] and all other advantages make this bacterium as a suitable candidate in future studies with the aim of its application in the food industry.

\section{Conclusions}

In the present study, we generate a food-grade L. lactis strain with the ability to secrete an antimicrobial peptide into the culture medium. The culture supernatant of the engineered L. lactis containing the peptide showed significant antibacterial activity against some foodborne pathogens. The purified recombinant peptide had antibiofilm formation and antioxidant activity and was also stable after boiling. Our in silico analysis showed that cLFchimera had strong affinity to DNA and LPS as two targets in bacteria by positive charged residues after molecular dynamic simulation. Overall, considering the appropriateness and the broad-spectrum antimicrobial activity of this chimeric peptide, it is recommended to evaluate this bioengineered $L$. lactis strain as a food preservative in future studies.

\begin{abstract}
Abbreviations
AMPs: Antimicrobial peptides; ANOVA: Analysis of variance; CFU: Colonyforming unit; CLFchimera: camel lactoferrin chimera; CLSI: Clinical and Laboratory Standards Institute; COM: Center of mass distances; DPPH: 2,2Diphenyl-I-picrylhydrazyl; EC 50 : Efficient Concentration; FDA: Food and drug administration; Glc: Glucose; GRAS: Generally recognized as safe; $I_{50}$ : Half maximal inhibitory concentration; LPS: Lipopolysaccharides; MD: Molecular Dynamic; MIC: Minimum inhibitory concentrations; MM/PBSA: Molecular mechanics/Poisson Boltzmann surface area; OD: Optical density; PBS: Phosphate-buffered saline; PCR: Polymerase chain reaction; RMSD: Root mean square deviation; ROS: Reactive oxygen species; SDS-PAGE: SDS polyacrylamide gel electrophoresis
\end{abstract}

\section{Acknowledgements}

The authors would also like to express their gratitude to the Ferdowsi University of Mashhad for their support.

\section{Authors' contributions}

MHS designed, supervised the study and wrote the manuscript. AT undertook all of the sample analysis and contributed to the writing of the manuscript. MM contributed to the design and writing of this manuscript. ZP and MHS carried out in silico analysis. All authors read and approved the final manuscript.

Funding

The present study was funded by Ferdowsi University of Mashhad with Grant No. 38736.

Availability of data and materials

All data generated or analyzed during this study are included in the article. Data sets from individual experiments can be obtained from the

corresponding authors upon reasonable request.

Ethics approval and consent to participate

Not applicable.

Consent for publication

Not applicable.

\section{Competing interests}

The authors declare that they have no competing interests.

\section{Author details}

${ }^{1}$ Department of Biotechnology and Plant Breeding, Faculty of Agriculture, Ferdowsi University of Mashhad, P.O. Box 91775-1163, Mashhad, Iran. ${ }^{2}$ School of Medicine, Shahroud University of Medical Sciences, Shahroud, Iran.

${ }^{3}$ Department of Animal Sciences, Faculty of Agriculture, Ferdowsi University of Mashhad, P.O. Box 91775-1163, Mashhad, Iran.

Received: 27 May 2019 Accepted: 6 March 2020

Published online: 30 March 2020

\section{References}

1. Abraham MJ, Murtola T, Schulz R, Páll S, Smith JC, Hess B, Lindahl E. GROMACS: high performance molecular simulations through multi-level parallelism from laptops to supercomputers. SoftwareX. 2015;1:19-25.

2. Ammons MCB, Ward LS, Fisher ST, Wolcott RD, James GA. in vitro susceptibility of established biofilms composed of a clinical wound isolate of Pseudomonas aeruginosa treated with lactoferrin and xylitol. Int J Antimicrob Agents. 2009;33(3):230-6.

3. Arqués JL, Rodríguez E, Langa S, Landete JM, Medina M. Antimicrobial activity of lactic acid bacteria in dairy products and gut: effect on pathogens. Biomed Res Int. 2015;2015:584183.

4. Berendsen HJ, Postma JP, van Gunsteren WF, Hermans J. Interaction models for water in relation to protein hydration. In: Intermolecular forces. Dordrecht: Springer; 1981. p. 331-42. 
5. Berendsen HJ, van der Spoel D, van Drunen R. GROMACS: a messagepassing parallel molecular dynamics implementation. Comput Phys Commun. 1995;91(1-3):43-56.

6. Bermúdez-Humarán LG, Aubry C, Motta JP, Deraison C, Steidler L, Vergnolle N, Chatel JM, Langella P. Engineering lactococci and lactobacilli for human health. Curr Opin Microbiol. 2013;16(3):278-83.

7. Birollo GA, Reinheimer JA, Vinderola CG. Viability of lactic acid microflora in different types of yoghurt. Food Res Int. 2000;33(9):799-805. https://doi.org/ 10.1016/S0963-9969(00)00101-0.

8. Bolscher JG, Adão R, Nazmi K, van den Keybus PA, van't Hof W, Amerongen $\mathrm{N}$, Bastos M, Veerman ECl. Bactericidal activity of LFchimera is stronger and less sensitive to ionic strength than its constituent lactoferricin and lactoferrampin peptides. Biochimie. 2009;91(1):123-32. https://doi.org/10. 1016/j.biochi.2008.05.019.

9. Bradford MM. A rapid and sensitive method for the quantitation of microgram quantities of protein utilizing the principle of protein-dye binding. Anal Biochem. 1976;72(1-2):248-54.

10. Brand-Williams W, Cuvelier ME, Berset CLWT. Use of a free radical method to evaluate antioxidant activity. LWT-Food Sci Technol. 1995;28(1):25-30.

11. Brogden KA. Antimicrobial peptides: pore formers or metabolic inhibitors in bacteria? Nat Rev Microbiol. 2005;3(3):238.

12. Coconnier MH, Liévin V, Hemery E, Servin AL. Antagonistic activity against helicobacter infection in vitro and in vivo by the human Lactobacillus acidophilus strain LB. Appl Environ Microbiol. 1998;64(11):4573-80.

13. Conesa C, Calvo M, Sánchez L. Recombinant human lactoferrin: a valuable protein for pharmaceutical products and functional foods. Biotechnol Adv. 2010;28:831-8. https://doi.org/10.1016/j.biotechadv.2010.07.002.

14. Daneshmand A, Kermanshahi H, Sekhavati MH, Javadmanesh A, Ahmadian M. Antimicrobial peptide, CLF36, affects performance and intestinal morphology, microflora, junctional proteins, and immune cells in broilers challenged with E. coli. Sci Rep. 2019;9(1):1-9.

15. del Castillo FJ, del Castillo I, Moreno F. Construction and characterization of mutations at codon 751 of the Escherichia coli gyrB gene that confer resistance to the antimicrobial peptide microcin B17 and alter the activity of DNA gyrase. J Bacteriol. 2001;183(6):2137-40

16. Devlieghere F, Vermeulen A, Chitosan DJ. Chitosan: antimicrobial activity, interactions with food components and applicability as a coating on fruit and vegetables. Food Microbiol. 2004;21(6):703-14. https://doi.org/10.1016/j. fm.2004.02.008.

17. Ebbensgaard A, Mordhorst H, Overgaard MT, Nielsen CG, Aarestrup FM, Hansen EB. Comparative evaluation of the antimicrobial activity of different antimicrobial peptides against a range of pathogenic bacteria. PLoS One. 2015;10:e0144611

18. El-Loly MM, Mahfouz MB. Lactoferrin in relation to biological functions and applications: a review. Int J Dairy Sci. 2011;6(2):79-111. https://doi.org/10. 3923/ijds.2011.79.111.

19. Eswar N, Webb B, Marti-Renom MA, Madhusudhan MS, Eramian D, Shen MY, Pieper U, Sali A. Comparative protein structure modeling using Modeller. Curr Protoc Bioinformatics. 2006;15(1):5-6.

20. Evans DJ, Holian BL. The nose-hoover thermostat. J Chem Phys. 1985;83(8):4069-74.

21. Hamzeh-Mivehroud M, Moghaddas-Sani H, Rahbar-Shahrouziasl M, Dastmalchi S. Identifying key interactions stabilizing DOF zinc finger-DNA complexes using in silico approaches. J Theor Biol. 2015;382:150-9.

22. Haney EF, Nazmi K, Bolscher J, Vogel HJ. Structural and biophysical characterization of an antimicrobial peptide chimera comprised of lactoferricin and lactoferrampin. Biochim Biophys Acta. 2012;1818(3):762-75. https://doi.org/10.1016/j.bbamem.2011.11.023.

23. Hartmann M, Berditsch M, Hawecker J, Ardakani MF, Gerthsen D, Ulrich AS Damage of the bacterial cell envelope by antimicrobial peptides gramicidin $S$ and PGLa as revealed by transmission and scanning electron microscopy. Antimicrob Agents Chemother. 2010;54(8):3132-42.

24. Helwigh $B$, Korsgaard $\mathrm{H}$. The community summary report on trends and sources of zoonoses, zoonotic agents, antimicrobial resistance and foodborne outbreaks in the European Union in 2006, European Food Safety Authority; 2007

25. Hickey CD, Sheehan JJ, Wilkinson MG, Auty MA. Growth and location of bacterial colonies within dairy foods using microscopy techniques: a review. Front Microbiol. 2015;6. https://doi.org/10.3389/fmicb.2015.00099.

26. Ho YH, Sung TC, Chen CS. Lactoferricin B inhibits the phosphorylation of the two-component system response regulators BasR and CreB. Mol Cell Proteomics. 2012;11(4):M111-014720.
27. Holo H, Nes IF. High-frequency transformation, by electroporation, of Lactococcus lactis subsp. cremoris grown with glycine in osmotically stabilized media. Appl. Environ Microbiol. 1989;55:3119-23.

28. Hou ZJL, Fang C, Zhou Y, Bai H, Zhang X, Luo X. Underlying mechanism of in vivo and in vitro activity of $\mathrm{C}$-terminal-amidated Thanatin against clinical isolates of extended-spectrum $\beta$-lactamase-producing Escherichia coli. J Infect Dis. 2011;203:273-82.

29. Jørgensen CM, Vrang A, Madsen SM. Recombinant protein expression in Lactococcus lactis using the P170 expression system. FEMS Microbiol Lett. 2014;351(2):170-8. https://doi.org/10.1111/1574-6968.12351.

30. Klingenberg C, Aarag E, Ronnestad A, Sollid JE, Abrahamsen TG, Kjeldsen G, et al. Coagulase-negative staphylococcal sepsis in neonates. Association between antibiotic resistance, biofilm formation and the host inflammatory response. Pediatr Infect Dis J. 2005;24(9):817-22.

31. Kollman PA, Massova I, Reyes C, Kuhn B, Huo S, Chong L, Lee M, Lee T, Duan Y, Wang W, Donini O. Calculating structures and free energies of complex molecules: combining molecular mechanics and continuum models. Acc Chem Res. 2000;33(12):889-97.

32. Kouzayaha, Nasir M, Buchet R. Antimicrobial peptides and their use in medicine Phys. Chem B. 2009;113:7012-9. https://doi.org/10.1134/50003683810090012.

33. Kumari R, Kumar R, Open Source Drug Discovery Consortium, Lynn A. g_mmpbsa-A GROMACS tool for high-throughput MM-PBSA calculations. J Chem Inf Model. 2014;54(7):1951-62.

34. Laskowski RA, MacArthur MW, Moss DS, Thornton JM. PROCHECK: a program to check the stereochemical quality of protein structures. J Appl Crystallogr. 1993;26(2):283-91.

35. Lemes A, Sala L, Ores J, Braga A, Egea M, Fernandes K. A review of the latest advances in encrypted bioactive peptides from protein-rich waste. Int J Mol Sci. 2016;17(6):950

36. Leon-Sicairos N, Canizalez-Roman A, de la Garza M, Reyes-Lopez M, ZazuetaBeltran J, Nazmi K, Gomez-Gil B, Bolscher JG. Bactericidal effect of lactoferrin and lactoferrin chimera against halophilic Vibrio parahaemolyticus. Biochimie. 2009;91(1):133-40.

37. Li T, Wang C, Yan X, et al. Antioxidant activity of Lactoferrin in vitro. Food Sci. 2012;33(21):111-3.

38. Linde A, Ross CR, Davis EG, Dib L, Blecha F, Melgarejo T. Innate immunity and host defense peptides in veterinary medicine. J Vet Intern Med. 2008;22(2):247-65.

39. Mason CK, Collins MA, Thompson K. Modified electroporation protocol for lactobacilli isolated from the chicken crop facilitates transformation and the use of a genetic tool. J Microbiol Methods. 2005;60(3):353-63. https://doi. org/10.1016/j.mimet.2004.10.013.

40. McKay LL, Baldwin KA. Applications for biotechnology: present and future improvements in lactic acid bacteria. FEMS Microbiol Lett. 1990;87(1-2):3-14.

41. Norrby K, Mattsby-Baltzer I, Innocenti M, Orally TS. Bovine lactoferrin systemically inhibits VEGF165-mediated angiogenesis in the rat. Int J Cancer. 2001;91(2):236-40. https://doi.org/10.1002/1097-0215.

42. Nosé S, Klein ML. Constant pressure molecular dynamics for molecular systems. Mol Phys. 1983;50(5):1055-76.

43. Oliver SP, Jayarao BM, Almeida RA. Foodborne pathogens in milk and the dairy farm environment: food safety and public health implications. Foodbourne Pathog Dis. 2005;2(2):115-29.

44. Omwandho CO, Kubota T. Salmonella enterica serovar Enteritidis: a minireview of contamination routes and limitations to effective control. Jpn Agric Res Q. 2010;44(1):7-16. https://doi.org/10.6090/jarq.44.7.

45. Oostenbrink C, Villa A, Mark AE, Van Gunsteren WF. A biomolecular force field based on the free enthalpy of hydration and solvation: the GROMOS force-field parameter sets 53A5 and 53A6. J Comput Chem. 2004;25(13): $1656-76$.

46. Pandey B, Grover A, Sharma P. Molecular dynamics simulations revealed structural differences among WRKY domain-DNA interaction in barley (Hordeum vulgare). BMC Genomics. 2018;19(1):132.

47. Parada $\mathrm{JL}$, Caron CR, Medeiros ABP, Soccol CR. Bacteriocins from lactic acid bacteria: purification, properties and use as biopreservatives. Braz Arch Biol Technol. 2007;50(3):512-42. https://doi.org/10.1590/S1516-89132007000300018.

48. Park CB, Kim HS, Kim SC. Mechanism of action of the antimicrobial peptide buforin II: buforin II kills microorganisms by penetrating the cell membrane and inhibiting cellular functions. Biochem Biophys Res Commun. 1998;244(1):253-7.

49. Pirkhezranian Z, Tanhaeian A, Mirzaii M, Sekhavati MH. Expression of Enterocin-P in HEK platform: evaluation of its cytotoxic effects on Cancer cell lines and its potency to interact with cell-surface glycosaminoglycan by molecular modeling. Int J Pept Res Ther. 2019;19(4):1-10. 
50. Pirkhezranian Z, Tahmoorespur M, Monhemi H, Sekhavati MH. Computational peptide engineering approach for selection the best engendered camel Lactoferrin-derive peptide with potency to interact with DNA. Int J Pept Res Ther. 2020a;19(6):1-10.

51. Pirkhezranian Z, Tahmoorespur M, Daura X, Monhemi H, Sekhavati MH. Interaction of camel Lactoferrin derived peptides with DNA: a molecular dynamics study. BMC Genomics. 2020b;21(1):60.

52. Rossi P, Giansanti F, Boffi A, Ajello M, Valenti P, Chiancone E, Antonini G. Ca2+ binding to bovine lactoferrin enhances protein stability and influences the release of bacterial lipopolysaccharide. Biochem Cell Biol. 2002;80(1):41-8.

53. Roy M, Kuwabara Y, Hara K, Watanabe Y, Tamai Y. Peptides from the N-terminal end of bovine lactoferrin induce apoptosis in human leukemic $(\mathrm{HL}-60)$ cells. J Dairy Sci. 2002;85(9):2065-74. https://doi.org/10.3168/jds. S0022-0302 (02)74284-7.

54. Safaeian L, Zabolian H. Antioxidant effects of bovine lactoferrin on dexamethasone-induced hypertension in rat. ISRN pharmacology, 2014.

55. Sim S, Wang P, Beyer BN, Cutrona KJ, Radhakrishnan ML, Elmore DE. Investigating the nucleic acid interactions of histone-derived antimicrobial peptides. FEBS Lett. 2017;591(5):706-17.

56. Singh PK, Parsek MR, Greenberg EP, Welsh MJ. A component of innate immunity prevents bacterial biofilm development. Nature. 2002;417(6888):552.

57. Sinha M, Kaushik S, Kaur P, Sharma S, Singh TP. Antimicrobial lactoferrin peptides: the hidden players in the protective function of a multifunctional protein. Int J Pept. 2013;2013. https://doi.org/10.1155/2013/390230.

58. Steidler L. Genetically engineered probiotics. Best Pract Res Clin Gastroenterol. 2003;17(5):861-76.

59. Steidler L, Hans W, Schotte L, Neirynck S, Obermeier F, Falk W, Fiers W, Remaut $\mathrm{E}$. Treatment of murine colitis by Lactococcus lactis secreting interleukin-10. Science. 2000;289(5483):1352-5.

60. Stepanović S, Vuković D, Hola V, et al. Quantification of biofilm in microtiter plates:overview of testing conditions and practical recommendations for assessment ofbiofilm production by staphylococci. APMIS. 2007;115:891-9.

61. Tahmoorespur M, Azghandi M, Javadmanesh A, Sekhavati MZ, MH. A novel chimeric anti-HCV peptide derived from camel Lactoferrin and molecular level insight on its interaction with E2. Int J Pept Res Ther. 2019;10(4):1-13.

62. Tanhaeian A, Ahmadi FS, Sekhavati MH, Mamarabadi M. Expression and purification of the main component contained in camel milk and its antimicrobial activities against bacterial plant pathogens. Probiotics Antimicrob Proteins. 2018c;10(4):787-93.

63. Tanhaeian A, Jaafari MR, Ahmadi FS, Vakili-Ghartavol R, Sekhavati MH. Secretory expression of a chimeric peptide in Lactococcus lactis: assessment of its cytotoxic activity and a deep view on its interaction with cell-surface Glycosaminoglycans by molecular modeling. Probiotics Antimicrob Proteins 2018d;11(3):1-8.

64. Tanhaiean A, Azghandi M, Razmyar J, Mohammadi E, Sekhavati MH. Recombinant production of a chimeric antimicrobial peptide in E. coli and assessment of its activity against some avian clinically isolated pathogens. Microb Pathog. 2018a;122:73-8.

65. Tanhaieian A, Sekhavati MH, Ahmadi FS, Mamarabadi M. Heterologous expression of a broad-spectrum chimeric antimicrobial peptide in Lactococcus lactis: its safety and molecular modeling evaluation. Microb Pathog. 2018;125:51-9.

66. Tang XS, Tang ZR, Wang SP, Feng ZM, Zhou D, Li TJ, Yin YL. Expression, purification, and antibacterial activity of bovine lactoferrampin-lactoferricin in Pichia pastoris. Appl Biochem Biotechnol. 2012;166(3):640-51. https://doi. org/10.1007/s12010-011-9455-0

67. Tang YL, Shi YH, Zhao W, Hao G, Le GW. Interaction of MDpep9, a nove antimicrobial peptide from Chinese traditional edible larvae of housefly, with Escherichia coli genomic DNA. Food Chem. 2009;115(3):867-72.

68. Van de Guchte M, Kok J, Venema G. Gene expression in Lactococcus lactis. FEMS Microbiol Lett. 1992;88(2):73-92.

69. Van der Kraan MI, Groenink J, Nazmi K, Veerman EC, Bolscher JG, Amerongen AVN. Lactoferrampin: a novel antimicrobial peptide in the N1domain of bovine lactoferrin. Peptides. 2004;25(2):177-83. https://doi.org/10. 1016/j.peptides.2004.12.006

70. Van Der Spoel D, Lindahl E, Hess B, Groenhof G, Mark AE, Berendsen HJ. GROMACS: fast, flexible, and free. J Comput Chem. 2005;26(16):1701-18.

71. Wakabayashi H, Yamauchi K, Kobayashi T, Yaeshima T, Iwatsuki K, Yoshie H. Inhibitory effects of lactoferrin on growth and biofilm formation of Porphyromonas gingivalis and Prevotella intermedia. Antimicrob Agents Chemother. 2009;53(8):3308-16.

72. Xiao R, Kisaalita WS. Iron acquisition from transferrin and lactoferrin by Pseudomonas aeruginosa pyoverdin. Microbiology. 1997;143(7):2509-15.
73. Yan J, Wang K, Dang W, Chen R, Xie J, Zhang B, Song J, Wang R. Two hits are better than one: membrane-active and DNA binding-related doubleaction mechanism of NK-18, a novel antimicrobial peptide derived from mammalian NK-lysin. Antimicrob Agents Chemother. 2013;57(1):220-8.

74. Yang L, Harroun TA, Weiss TM, Ding L, Huang HW. Barrel-stave model or toroidal model? A case study on melittin pores. Biophys J. 2001;81(3):147585. https://doi.org/10.1016/S0006-3495(01)75802-X.

\section{Publisher's Note}

Springer Nature remains neutral with regard to jurisdictional claims in published maps and institutional affiliations.
Ready to submit your research? Choose BMC and benefit from:

- fast, convenient online submission

- thorough peer review by experienced researchers in your field

- rapid publication on acceptance

- support for research data, including large and complex data types

- gold Open Access which fosters wider collaboration and increased citations

- maximum visibility for your research: over $100 \mathrm{M}$ website views per year

At BMC, research is always in progress.

Learn more biomedcentral.com/submissions 